\title{
PREPRINT
}

Citation for this manuscript:

Tozzi, A. (2018, September 1). Sonny Liston and the torn tendon. https://doi.org/10.31236/osf.io/2p7w6

\section{SONNY LISTON AND THE TORN TENDON}

\author{
Arturo Tozzi, MD, PhD, AAP \\ Center for Nonlinear Science, University of North Texas, PO Box 311427, Denton, TX 76203-1427, USA \\ tozziarturo@libero.it
}

The first Liston-Clay fight in 1964 is still highly debated, because Liston quitted at the end of the sixth round claiming a left shoulder injury. Here we, based on the visual analysis of Sonny's movements during the sixth round, show how a left shoulder's rotator cuff tear cannot be the cause of the boxer failing to answer the bell for the seventh round.

KEYWORDS: boxing; Muhammad Ali; World Heavyweight Championship; Miami Beach; rotator cuff injury

The first fight between Sonny Liston and Cassius Clay took place on February 25, 1964 in Miami Beach. Liston failed to answer the bell for the seventh round and Clay was declared the winner by technical knockout (Remnick, 2000). The fight is one of the most controversial ever: it was the first time since 1919 that a World Heavyweight Champion had quit sitting on his stool. Liston said he had to quit because of a left shoulder injury (Tosches, 2000). However, there has been speculation since about whether the injury was severe enough to actually prevent him from continuing. It has been reported that Sonny Liston had been long suffering from shoulders' bursitis and had been receiving cortisone shots, despite his notorious phobia for needles (Assael 2016). In training for the Clay fight, it has been reported that he reinjured his left shoulder and was in pain when striking the heavy bag. He secretly resorted to heavy icing and ultrasound therapy after each training session. Immediately after the fight, Liston told broadcasters that he hurt the shoulder in the first round. Dr. Alexander Robbins, chief physician for the Miami Beach Boxing Commission, diagnosed Liston with a torn tendon in his left shoulder. During the night, a team of eight doctors inspected Liston's arm at St. Francis Hospital in Miami Beach and agreed that it was too badly damaged for Liston to continue fighting (Gallender 2012). The torn tendon had bled down into the mass of the biceps, swelling and numbing the arm. Those findings were confirmed in a formal investigation immediately after the fight by Florida State Attorney Richard Gerstein, who noticed that there was little doubt that Liston went into the fight with a sore or lame shoulder (Maule, 1964).

Here we provide an analysis of the fight movie, is order to evaluate whether Liston's left arm was damaged enough to prevent him to fight.

\section{MATERIALS AND METHODS}

Signs and symptoms rotator cuff injuries. Rotator cuff injuries range from acute reversible tendinitis to massive tears involving the supraspinatus, infraspinatus, and subscapularis. Despite traumatic rotator cuff tears may occur quickly or under heavy load (e.g., lifting a heavy weight) (Craig et al., 2017), the most common cause is repeated micro-trauma, which may occur over several weeks, months or years. In particular, repetitive overhead activities involving the rotator cuff are frequent in several overhead sports activities. To make an example, tennis players and baseball pitchers are especially vulnerable to overuse tears (Shaffer and Huttman, 2014; Menge et al., 2015). Indeed, imbalance between opposing muscle groups (the concentrically contracting muscles that generate force and the eccentrically contracting ones that control movement) may result in overuse injuries of the shoulder.

The main symptoms reported in rotator cuff injuries are: pain, weakness, instability, limited range of motion (ROM) (Moosikasuwan et al., 2005). Other associated symptoms may provide helpful information: swelling, numbness, loss of motion, catching or popping of the shoulder. Symptoms may be relatively acute, either following an injury, or associated with a known repetitive overuse activity. Inspection may reveal swelling, atrophy, asymmetry. Supraspinatus and infraspinatus atrophy can be observed in massive rotator cuff tears and in entrapments of the suprascapular nerve. Despite scapular winging is rare, scapulothoracic motion is often impaired. The biceps tendon can become inflamed and painful. 
The active and passive ROM in all planes and scapulohumeral rhythm can be impaired. During active shoulder elevation, patients tend to have a decrease in glenohumeral and an increase in scapulothoracic joint motion (Steinbeck et al, 1998; Wuelker et al., 1998). Also, decreased active elevation with normal passive ROM is usually observed in rotator cuff tears, secondary to pain and weakness. When both active and passive ROM are equally decreased, this suggests onset of adhesive capsulitis. Overhand throwers often develop excess external rotation (up to $15-20^{\circ}$ ) on the throwing side, usually accompanied by loss of internal rotation on the same side. The impingement syndrome that can be associated with rotator cuff injuries tends to cause pain with elevation ranging from $60-120^{\circ}$. Significant weakness in external rotation is observed in large rotator cuff tears (infraspinatus and teres minor). The dropping of the arm with the elbow extended, in either thumbs down and up position, usually indicates a significant supraspinatus muscle tear. When the patient's shoulder is abducted to $90^{\circ}$ and then the arm is lowered slowly to the side in the same arc of movement, severe pain or inability to slowly return the arm to the side indicates a rotator cuff tear. When the shoulder is forcibly forward flexed and internally rotated, the occurrence of pain indicates an overuse injury to the supraspinatus muscle and possibly to the biceps tendon. When the arm is maximally elevated through forward flexion, pain indicates a positive test result for impingement. When the shoulder and elbow are forward flexed to $90^{\circ}$ and then the shoulder is internally rotated, pain indicates supraspinatus tendon and greater tuberosity impingement under the coracoacromial ligament and coracoid process. When the examiner forward flexes the arms to $90^{\circ}$ and then forcibly internally rotates the shoulder, the occurrence of pain indicates supraspinatus tendonitis.

Assessing possible Liston's rotator cuff injuries. We carefully examined the frames of the original match movie. The assessed movie was taken from: Youtube. "Cassius Clay aka Muhammad Ali v Sonny Liston 1964”. Published in 2012, Channel: MIchel Bresson. Length: 35 minutes and 36 seconds. In particular, we evaluated the sixth round, e.g., the round before Liston's quit. We examined the movements performed by both Sonny's arms, looking for the above described signs and symptoms of rotator cuff injuries. Also, we calculated how many times Liston used the right and the left arm the sixth round, in order to punch and counteract Clay's attacks.

\section{RESULTS}

No signs of arm swelling and numbing were detectable through a careful inspection of the single frames of the last, sixth round. Furthermore, no symptoms of shoulders' weakness, instability, limited range of motion were noticed. The active and passive range of shoulder joints motion was preserved. The internal and external rotations of the arms, together with flexion and extension of the elbows, did not seem to be impaired. During the sixth round, Sonny Liston raised the left arm 22 times and the right one just 3 times. He carried the right arm at belt level throughout the whole round. In sum, Liston moved the left arm in the ordinary way.

\section{CONCLUSIONS}

A rotator cuff tear is very common in sport activities characterized by repetitive lifting or overhead movements. As stated above, the diagnosis of rotator cuff tear in shoulder is characterized by peculiar signs and symptoms. It should be noticed that some rotator cuff tears are not painful, but may still result in arm weakness. At first, the pain may be mild and only occur when lifting the arm over the head. However, over time, the pain may become more noticeable. Shoulder pain and weakness increases with the severity of rotator cuff tear. In this case, the most important symptom is a reduction in shoulder function. In case of a small rotator cuff tear, the patient can often still raise the arm with or without pain, while moderate tears are usually very painful and impair motility. Indeed, partial rotator cuff tear may present just with mild shoulder pain, clicking during shoulder elevation, and mild shoulder weakness lifting the hand above shoulder height, or reaching behind the back. In turn, full thickness rotator cuff tear will generally cause severe shoulder pain and inability to lift the elbow away from the body. In some cases, the rotator cuff tear is so severe that a significant number of pain fibres are also torn, which can make them less painful, but very weak.

When inspecting the movie frames of the Liston-Clay match, the typical signs and symptoms of a rotator cuff tear (i.e., pain when lifting and lowering arm or following specific movements, and weakness when lifting or rotating the arm) were not noticed in Liston's boxing activity. Furthermore, in the sixth round, Liston used mostly the left arm, e.g., the one that was later said to be injured. If the boxer had the left-arm partially or totally injured, it would have used the right one, in order to avoid the pain and to address the left shoulder's impaired motility. This means that Liston's left arm was not damaged enough to prevent him to fight.

\section{REFERENCES}

1) Assael S. 2016. The Murder of Sonny Liston: Las Vegas, Heroin, and Heavyweights. Blue Rider Pr.

2) Craig R, Holt T, Rees JL. 2017. Acute rotator cuff tears. BMJ. 2017 Dec 11;359:j5366. doi: 10.1136/bmj.j5366.

3) Gallender PR. 2012. Sonny Liston - The Real Story Behind the Ali-Liston Fights. CreateSpace Independent Publishing Platform. ISBN-13: 978-1478185185 
4) Maule T. 1964. "Yes, it was good and honest". Sports Illustrated: 20, March 9, 1964)..

5) Menge TJ, Byram IR, Boykin RE, Bushnell BD. 2015. Labrum and rotator cuff injuries in the throwing athlete. Phys Sportsmed. 2015 Feb;43(1):65-72. doi: 10.1080/00913847.2015.1005546. Epub 2015 Jan 20.

6) Moosikasuwan JB, Miller TT, Burke BJ. 2005. Rotator cuff tears: clinical, radiographic, and US findings. Radiographics. 2005 Nov-Dec;25(6):1591-607.

7) Remnick D. 2000. King of the World: Muhammed Ali and the Rise of an American Hero. Vintage Books Ed. ISBN: 978-0-375-70229-7 (0-375-70229-6)

8) Shaffer B, Huttman D. 2014. Rotator cuff tears in the throwing athlete. Sports Med Arthrosc Rev. 2014 Jun;22(2):101-9. doi: 10.1097/JSA.0000000000000022.

9) Steinbeck J, Liljenqvist U, Jerosch J. 1998. The anatomy of the glenohumeral ligamentous complex and its contribution to anterior shoulder stability. J Shoulder Elbow Surg. 1998 Mar-Apr. 7(2):122-6. [Medline].

10) Tosches N. 2000. The Devil and Sonny Liston. Little, Brown and Company (Boston, New York, London) .

11) Wuelker N, Korell M, Thren K. 1998. Dynamic glenohumeral joint stability. J Shoulder Elbow Surg. 1998 JanFeb. 7(1):43-52. 